EPJ Web of Conferences 33, 01005 (2012)

DOI: $10.1051 /$ epjconf/20123301005

(C) Owned by the authors, published by EDP Sciences, 2012

\title{
Is Advanced Real-Time Energy Metering Sufficient to Persuade People to Save Energy?
}

\author{
L.Ting ${ }^{1, \mathrm{a}}$, H. Leite ${ }^{2, \mathrm{~b}}$ and T. Ponce de Leão ${ }^{3, \mathrm{c}}$ \\ ${ }^{1}$ College of Business, National Taipei University, Taiwan \\ ${ }^{2}$ INESC TEC/FE/UP, University of Porto - Faculty of Engineering, Portugal \\ ${ }^{3}$ LNEG, Portugal
}

\begin{abstract}
In order to promote a low-carbon economy, EU citizens may soon be able to check their electricity consumption from smart meter. It is hoped that smart meter can, by providing real-time consumption and pricing information to residential users, help reducing demand for electricity. It is argued in this paper that, according the Elaborative Likelihood Model (ELM), these methods are most likely to be effective when consumers perceive the issue of energy conservation relevant to their lives. Nevertheless, some fundamental characteristics of these methods result in limited amount of perceived personal relevance; for instance, energy expenditure expense may be relatively small comparing to other household expenditure like mortgage and consumption information does not enhance interpersonal trust. In this paper, it is suggested that smart meter can apply the "nudge" approaches which respond to ELM as the use of simple rules to make decision, which include the change of feedback delivery and device design.
\end{abstract}

\section{The Need for Energy Conservation}

The European Union (EU) currently imports $82 \%$ of its oil and $57 \%$ of its gas, making it the world's leading importer of these fuels [1]. In 2007, the EU sets a common energy policy which intends to promote a low-carbon economy with the aim to increase competition in the energy markets, improve security of supply and increase employment $[2,3]$. As a key proposal a $20 \%$ cut in greenhouse gas emissions from all primary energy sources by 2020 is established (compared to the 1990 levels), while pushing for an international agreement aimed to achieve a $30 \%$ cut from all developed nations by around the same time.

Currently, around $40 \%$ of the EU energy requirements are related to buildings and is being the focus for several initiatives [4]. It is believed by engineers and policy makers that energy conservation in households can be achieved through passive and active measures. By passive measures we mean, envelop measures that make the buildings with greater inertia and though needing less energy for heating and cooling. By active measures we mean more efficient use of energy that leads to decreased energy consumption together with local use of renewable energy. To incentivise active measures, EU citizens may soon be able to check their electricity consumption from a display located somewhere more prominent than the actual meter, or even online using Internet or smartphone. This interactive communication technology is the so-called smart meter.

For most Utilities, investing in smart meter is based on the increase of operational efficiencies the device can produce. On the other hand it is also hoped that smart meter can, by providing real-time consumption and pricing information to residential users, helps in reducing demand for electricity [5]. Nevertheless, in this paper it is argued that such expectation does not take into account the

\footnotetext{
a e-mail : lucyting@gm.ntpu.edu.tw

b e-mail : hleite@fe.up.pt

be-mail : teresa.leao@lneg.pt
}

This is an Open Access article distributed under the terms of the Creative Commons Attribution License 2.0, which permits unrestricted use, distribution, and reproduction in any medium, provided the original work is properly cited. 
complexity of how consumer processes information, and thus the effectiveness of smart meter as a behaviour-change agent could be compromised.

The aim of this paper is to evaluate the effectiveness of smart meter from the perspective of energy consumers and provide insights to smart meter developers on how their devices may engage with household consumers. This paper is structured firstly by outlining smart meter and its functions to residential consumers. It is followed by a discussion of how consumers process information as well as an evaluation of the price- and information-based behaviour change strategies. It will ends with suggestions for smart meter development.

\section{Smart Metering: Technology and Tendency}

The actual residential electricity meters measure the amount of energy consumed in the unit of kilo-watt hour. In addition, these electricity meters are able to establish billing cycles and energy used during a cycle. "Time-of-day" metering allows electric rates to be changed during a day, to record usage during peak high-cost periods and off-peak lower-cost, periods. Normally these functions are all that these meters can provide.

With the introduction of smart meter, which is going to replace the current residential electricity meter, the consumption of electric energy can be recorded in small intervals of minutes and communicates the collected data back to the utility for monitoring and billing purposes. The tendency is for the data to be recorded in small intervals of 15 minutes, transmitted by radio to a nearby radio collector which then sends the data to the utility through a wireless network. Thus, this data becomes available online and can then be managed for the residential customers via their electronic devices such as computers and smart phones.

The electricity suppliers through a smart meter can offer a lot more services to their customers, including a pre-pay offer, peak day alert (with sms or email), peak day pricing protection plan, and additional save-up services as a challenge to save energy using a social network community (e.g. biggest loser neighbourhood challenge). In addition, the electricity supplier can also give customers the possibility to take control over heavy loads through relays and thus ask costumers for demand response shedding of loads during peak load periods.

In terms of tariff options, the residential consumers can go from a fixed tariff or time-of-use tariff to a variable tariff, or even to a dynamic pricing tariff. The rationale behind the dynamic price billing option is to penalise consumer for uses of energy at peak times. Changes in the normal electric usage pattern over time are called demand response. Customers are expected to change their normal behaviour following "price-based demand response" (like real-time pricing, critical-peak pricing, and time-of-use rates) and "incentive-based demand response" (the load reductions requested either when the grid operator thinks reliability conditions are compromised or when prices are too high.

\section{Consumer Information Processing}

There are two tools with which smart meter employs to manipulate behaviour change: real-time consumption information and pricing information. Together and/or separately it is hoped that these information would keep users aware of how much electricity they use as well as how much it costs them. Hopefully users would then have higher intention to save energy before actually doing it. However, according to the Elaboration Likelihood Model (ELM) [19], a person processes a given information on the basis on how relevant he thinks the information is to him.

The ELM model suggests that, when a receiver thinks the messages is relevant, it is likely that he will attend closely to the presented information, carefully scrutinise the arguments it contains, and reflect on other issue-relevant considerations. When positive attitude towards the issue is developed as a result, the chances for the person to act on the issue also increase. On the other hand, when a person does not perceive the information relevant, he will probably employ some simple decision 
rules to evaluate the advocated position. Examples of the rules include using a rule of thumb, an educate guess, an intuitive judgment or common sense.

Both the information-based and price-base approach relies on people's engagement in the former route. That is, people would consider the issue of energy saving is relevant to them. Yet it may not always be the case for residential users.

\subsection{Myth 1: Price Persuades}

Many policymakers and economists use price-based strategies with the hope that extra monetary costs can increase a person's feeling of relevance to energy saving and therefore lower energy consumption. Pricing information, which is displayed on smart meter or on the web, aims to remind customers the potential penalty of using energy in peak time. Thus the chances are expected to increase for people to be coerced to save energy for self-interested reasons like cost saving.

Nevertheless, considering that energy costs usually accounts for only a small fraction of a fixed monthly expense, compared to for example house mortgage and insurance, consumers may not be as involved and sensitive to price changes as expected. Lower-income householders on the other hand may be more sensitive compared to those with higher-income [5], yet they are less likely to be the ones who contribute to the most of energy consumption and need to cut down their use of electricity.

Electricity operates at the level of sub-consciousness within a home [5], and its importance is deeply felt when the level of comfort is jeopardised for energy saving (i.e. no air conditioning in mid-summer). Even though people may have dissimilar levels of minimum comfort, in situation when the physical and psychological costs become too high to save energy (i.e. too hot to bear), people may respond more insensitively to price increase.

\subsection{Myth 2: Consumption Information Persuades}

There is a chance that factual information on energy consumption could influence people's decision to save resources [10]. However the majority of energy users take little or no interest in managing their usage [11], and with the lack of motivation, information-feeding may not be sufficient to trigger behaviour change.

The benefits of resource conservation are established based on individual sacrifice of energy use, since the primary beneficiary is the environment and the community as a whole. Ironically people who use energy carelessly would have more personal comfort than those who do not. Thus for people who are less motivated for environmental purposes, the fact that there may be free riders could make them even less involved and less motivated to practice energy conservation [6]. Additionally direct display of the household energy consumption information shows little relevance to establish such interpersonal trust, which may turn people further away from interpreting information rationally and carefully.

Positive attitude of an issue does not always lead to actions toward it [18]. In other words, even though information feeding may have positive impact on attitude towards energy conservation, it does not necessarily make people start saving electricity at home. This is especially the case when people do not perceive the issue relevant to their daily life, as well as when they do not have personal experience on the negative consequences [18]. Changes of climate or other environmental impacts of energy over-consumption may not be immediately felt, and the fact that energy is used at an unconscious level within a home [5] would compromise the chances for information to be an effective behaviour change agent in the case of energy conservation.

\section{Suggestions for Smart Meter Development}

Recently behaviour economists propose the use of "nudge" as an alternative (and effective) solution to replace the price-based and information-based approach. The term "nudge" refers to the use of environmental cues to alter people's behaviour in a predictable way without forbidding other alternatives or significantly changing the economic incentives [7]. Using the framework of ELM, 
people can be nudged to change their behaviour voluntarily, even when they do not perceive the issue relevant to them.

The appeal of nudge is obvious as it proposes a set of solutions without the cost of legislation, regulation and intervention. Thus it has generated great interest among policy makers worldwide, including the US and the UK government. The concept of "nudge" can be applied to smart meter from two aspects: how feedback information is delivered and how the device is designed.

\subsection{Feedback Delivery}

Different persuasion principles have been studied in the marketing and social psychology literature which are also applicable to the sphere of energy saving. It is found that people often wish to be accepted by other people and would tend to behave like other in specific situations. By testing how social norm may influence energy consumption, Schultz and his colleagues found that, highusage consumers would voluntarily reduce their use when they become aware that they consume more than their neighbours [8]. On the other hand, a smiley face indicating social approval would limit the chances for low-usage consumers to use more energy when they realise their consumption is lower than their neighbours. Likewise smart meter can present, apart from household consumption, real-time average consumption information in the neighbourhood and symbols to indicate social approval or disapproval.

People are found to still be persuaded subliminally even when they are not consciously aware of the messages presented to them [14]. When it comes to energy consumption, even when people are presented to symbols indicating social approval for as short as 25 milliseconds, they would still show signs of being influenced compared to people without any presentation of the symbols at all [15]. This finding provides another nudge tool for smart meter in which the device can choose to subconsciously influence the householders, manipulating the length of time they are exposed to the symbols and still achieve similar outcome.

It is also found that people are sensitive to how information is presented [12]. When a message is focused on the losses (negative frame, ie. it will cost you a lot), people will prefer to take risks; whereas they will try to avoid risks when the message is focused on gains (positive frame, ie. it will save you a lot). When promoting environmentally friendly energy consumption, women, people younger than 35 and older than 55 years, lower educated and less pro-environmental people are more affected to how messages are framed and respond better to positively framed messages than negatively framed ones [13]. Smart meter similarly can also present consumption feedback using the frame effect and, for example, remind high usage consumers who fits into the demographic profile how much money they could save.

\subsection{Device Designs}

Equally people can be seduced by the look and functions that the design of smart meter offers; for example people may change their behaviour voluntarily when being reminded promptly. Let us analyse some examples: (1) a flashing light was used to alert a sample of American householders that the outdoor temperature had dropped below $68^{\circ} \mathrm{F}$ and it was time to turn off the air-conditioning and instead open windows for cooling [18]. (2) Similarly an "energy orb" which changes colour according to the time-of-use tariff in operation can remind users to reduce consumption in advance of the peak time [16]. Likewise smart meter can incorporate ambient design such as alarming users to subtly influence user behaviour when consumption level increases.

The choice of colour in a product design is an important decision as colour can evoke strong product association and category imageries [17]. Overall warm colours such as red are psychically and emotionally arousing, exciting and distracting; cool colours like green and blue on the other hand are relaxing, peaceful, calm and pleasant. When it comes to energy conservation, colour green is commonly used and associated with the environment and the concept of eco-friendly. When designing smart meter, engineers could also incorporate variation of colour to induce subconscious response of behaviour change. 


\section{$2^{\text {nd }}$ European Energy Conference}

Just like some women show off with their designer brand handbags to insinuate their social prestige, the act of energy conservation could also be driven by the desire to publicly demonstrate altruism. It is found that some people are willing to pay extra premium price for Toyota Prius, a hybrid car, for its unique identifiable shape which can be easily spotted in the public and suggests a high level of moral concern to the environment [9]. Similar results are also found in purchase of solar panel mounted on the top of house roofs. This is referred as conspicuous conservation. Since smart meter is usually installed on the outside wall of a house visible to the public, it can possibly take advantage of the same underlying psychological principle to achieve higher and better use of the device.

\section{Final Remarks}

It has been established in this paper that the persuasion method commonly used by smart meter, price-based and information-based approach, may not necessarily succeed in making energy users to start saving energy. According to the Elaborative Likelihood Model (ELM), they are most likely to be effective when consumers perceive the issue of energy conservation relevant to their lives. Price increase may have impact, yet the effect would be limited because, for example energy expense may be relatively small comparing to other household expenditure like mortgage. Information of energy consumption does not always induce voluntarily energy conservation when, for instance, interpersonal trust is not enhanced.

This paper has also made suggestion to a number of "nudge" approaches which smart meter can apply to influence energy users without costing them too much psychological efforts, including feedback delivery and device design. Fundamentally these methods respond to ELM using simple rules to facilitate decision making when the issue is considered of little personal relevance. Smart meter can provide neighbourhood consumption information as a comparison base to household consumers, as well as use symbols to indicate social approval / disapproval. Additionally, short exposure to subliminal message and positively framed message can also be adopted. In terms of device design, smart meter can incorporate ambient features like alarm, variation of colour and eyecatching design to increase the chances to nudge consumers to save energy.

\section{References}

1. The Association Press (2007) Low-carbon economy' proposed for Europe, accessed on Nov 2011

2. European Commission Green Paper (2006) A European Strategy for Sustainable, Competitive and Secure Energy COM 105 final, accessed on Nov 2011

3. Communication from the Commission to the European Council and the European Parliament (2007) An Energy Policy for Europe COM 1 final, accessed on Nov 2011

4. European Commission, Directorate-General for Energy and Transport (2010), Energy Efficiency in Buildings, accessed on Nov 2011

5. S. Darby, Building Research \& Information, 38(5), 442-457 (2010)

6. D. Wiener, Journal of Marketing 55(2), 38-47(1991)

7. R.H. Thaler, R. C. Sunstein, Nudge: Improving decision about health, wealth and happiness (2008)

8. W.P. Schultz, J. M. Nolan, R. B. Cialdini, N. J. Goldstein, V. Griskevicius, Psychology Science, 18(5), 429-434 (2007)

9. S. E. Sexton, A. L. Sexton, Working Paper, University of California, Centre for Energy and Environmental Economics (2011), access by Feb 2012

10. S. Darby, Environmental Change Institute, University of Oxford, Oxford (2006), accessed on Jan 2012

11. M. Valocchi, A. Schurr, J. Juliano, E. Nelson, IBM, Somers, NY (2010), accessed on Jan 2012

12. A. Tverskey, D. Kahneman, Journal of Business, 59, 251-278, (1986)

13. L. Van de Velde, W. Verbeke, M. Popp, G. Van Huylenbroeck, Energy Policy, 38(2010), 55415549 (2010) 
14.E.J. Strahan, S.J. Spencer, M.P. Zanna, Journal of Experimental Social Psychology, 38, 556568, (2002)

15. C. Seligman, J. J. Darley, L. J. Becker, Energy and Building 1, pp. 325-337 (1978)

16. M. S. Martinez, C. R. Geltz, Utilizing a pre-attentive technology for modifying customer energy usage, Proceedings, European Council for an Energy-Efficient Economy, (2005)

17. M. M. Aslam, Journal of Marketing Communications, 12(1), 15-30, (2006)

18. D. O'Keefe, Persuasion: Theory and Research (1990)

19. R. E. Petty, and J. T. Cacioppo, Communication and Persuasion: Central and Peripheral Routes to Attitude Change (1986). 